\title{
Application of Spray Drying Particle Engineering to a High-Functionality/Low-Solubility Milk Thistle Extract: Powders Production and Characterization
}

\author{
Francesca Sansone ${ }^{1, *}$, Tiziana Esposito ${ }^{1,2}$, Maria Rosaria Lauro ${ }^{1, *}(\mathbb{D})$, Patrizia Picerno ${ }^{1}$, \\ Teresa Mencherini ${ }^{1}$ (1) , Franco Gasparri ${ }^{1}$, Stefania De Santis ${ }^{3}$, Marcello Chieppa ${ }^{2,3,4}$, \\ Claudia Cirillo ${ }^{5}$ and Rita Patrizia Aquino ${ }^{1}$ \\ 1 Department of Pharmacy, University of Salerno, via Giovanni Paolo II, 132, 84084 Fisciano, Italy; \\ tesposito@unisa.it (T.E.); ppicerno@unisa.it (P.P.); tmencherini@unisa.it (T.M.); info@gasparrifranco.it (F.G.); \\ aquinorp@unisa.it (R.P.A.) \\ 2 PhD Program in Drug Discovery and Development, University of Salerno, via Giovanni Paolo II, 132, \\ 84084 Fisciano, Italy; mchieppa@unisa.it \\ 3 IRCCS “de Bellis", Laboratory of Experimental Immunopathology, 70013 Castellana Grotte, Italy; \\ s-desantis@live.it \\ 4 EBRIS, European Biomedical Research Institute of Salerno, 84121 Salerno, Italy \\ 5 Department of Industrial Engineering and NANO_MATES Research Centre, University of Salerno, \\ via Giovanni Paolo II, 132, 84084 Fisciano, Italy; clcirillo@unisa.it \\ * Correspondence: fsansone@unisa.it (F.S.); lauro@unisa.it (M.R.L.)
}

Received: 7 June 2018; Accepted: 11 July 2018; Published: 14 July 2018

\begin{abstract}
Many natural compounds having antioxidant and anti-inflammatory activity are a potential target for new therapies against chronic inflammatory syndromes. The oral administration of functional herbal supplements may become a prevention strategy or therapy adjuvant for susceptible patients. A case study is our milk thistle (Silybum marianum) extract rich in silymarin complex. A water-soluble microencapsulated powder system was developed by a spray drying technique to improve the poor silymarin bioactivity after oral administration. Sodium carboxymethylcellulose (NaCMC) was employed as coating/swelling polymer matrix and sodium lauryl sulfate (SLS) as the surfactant (1:1:0.05 w/w/w). A $\mathrm{H}_{2} \mathrm{O} / \mathrm{EtOH} /$ acetone $(50 / 15 / 35 v / v / v)$ solvent system was used as liquid feed. The microsystems were capable of improving the in vitro dissolution and permeation rates, suggesting an enhancement of bioactivity after oral administration. The microsystems protect the antioxidant activity of silymarin after harsh storage conditions period and do not affect the anti-inflammatory properties of the raw extract (efficient already at lower concentrations of $0.312 \mathrm{mg} / \mathrm{mL}$ ) to reduce dendritic cells (DCs) inflammatory cytokine secretion after lipopolysaccharide administration. This approach allows managing particle size, surface properties and release of bioactive agents improving the bioactivity of a herbal supplement and is also possibly applicable to many other similar natural products.
\end{abstract}

Keywords: silymarin complex; water solubility; in vitro dissolution and permeation tests; anti-inflammatory activity; functional stability

\section{Introduction}

Plant extracts intake has been associated with numerous health benefits, but their efficacy is often limited due to insufficient dose efficiency after oral administration. To be consumed as part of a daily diet or as a dietary supplement, the absorption and bioavailability of nutraceuticals must sustain a significant therapeutic level when orally ingested [1]. The compound must be 
dissolved or dispersed in the aqueous intestinal lumen, to become accessible for absorption. A way to enhance the absorption after the oral administration as well as, targeted biological efficacy is to produce technological delivery systems able to improve dissolution and permeation rate of the active ingredient [2,3]. Numerous delivery systems had been developed and studied extensively in oral drug delivery [4-6], but the application of this research area to nutraceuticals only is emerging very recently [7-12]. The milk thistle (Silybum marianum (L.) Gaertn, Asteraceae), extract is an essential source of silymarin; it is a well-known complex of flavonolignans (silybin A and B, isosilybin A and B, silydianin, and silychristin) and flavonoids (taxifolin and quercetin) used to treat a variety of ailments like liver (hepatitis, cirrhosis, and icterus), kidney, and gallbladder problems [13,14]. Silybin is the primary and most active component of silymarin complex; it is a potent antioxidant able to reduce inflammation, also having membrane-stabilizing, hepatoprotectant, anticarcinogenic and antiviral activities [15]. Silymarin also has got significant anti-cancerous properties towards prostate cancer, but it is inadequately utilized for cancer therapy due to its hydrophobic nature and poor bioavailability [16]. The extensive phase II metabolism, low permeability across epithelial cells, low aqueous solubility, and rapid excretion in bile and urine [15]. These are characteristics that make it unstable and poorly absorbed from gastrointestinal tract. These factors need a form of silymarin able to overcome absorption problems $[13,17]$. During past years several approaches have been used to augment Silymarin bioavailability after oral administration such as complexation with phospholipids [18], niosomes [19] and liposomes [20-22], inclusion complex with $\beta$-cyclodextrins [23], incorporation in solid dispersions [24], formation of derivatives (salt, prodrug, and glycosides) as well as micronization and nanonisation [25]. In a recent work, silymarin poly(D,L-lactic-co-glycolic acid) (PLGA) nanoparticles (NPs) have been developed to improve the therapeutic efficacy of silymarin towards prostate cancer by single emulsion solvent evaporation technique [16]. Conventional liposomes, mainly composed of phospholipids and cholesterol, are susceptible to disintegration due to the effects of the gastric acid, pancreatic lipase, and intestinal bile salts; thus, more recently, stable hybrid liposomes-encapsulated silymarin [26] and novel vesicular nanosystem bilosomes loading silymarin have been produced and compared to conventional liposomes, aiming at increasing the hepatoprotective activity of the drug [27].

The selection of technique and compositional materials to produce the delivery system plays an essential role in developing a functional, safe and marketable product [28,29]. On this trend, microencapsulation by spray drying technique is a cost-effective one-step process as compared to other encapsulation methods [23]. It is a micro-/ nanoencapsulation technique mainly used in food and pharmaceutical trade in processing materials very rapidly while providing relative control of the final product properties $[30,31]$. In this study, we produced a water-soluble spray-dried powder to encapsulate the silymarin rich milk thistle extract. Technological characteristics (process yield, loading efficiency, solid state) as well as in vitro dissolution and permeation behavior of microencapsulated extract have been investigated to unprocessed one. The silymarin content and antioxidant activity of the new herbal supplement were evaluated before and after a storage period under harsh conditions.

The anti-inflammatory activity of the extract after the process transformation was performed in vitro cultured dendritic cells (DCs) exposed to microencapsulated or raw extract. Intestinal DCs are the immune cells most frequently exposed to nutritional derived products. Differently, from DCs resident in non-mucosal tissues, intestinal DCs are conditioned by the host and environmental factors to become inflammatory impaired [32]. As DCs precursors become inflammatory impaired once exposed to the intestinal milieu and intestinal DCs can extend process into the intestinal lumen [33,34], we evaluated silymarin abilities to prevent LPS induced inflammatory cytokines secretion, as previously demonstrated for quercetin [35-37]. Furthermore, we compared the microencapsulated with to the raw extract showing that microencapsulation does not reduce silymarin anti-inflammatory abilities. 


\section{Results and Discussion}

\subsection{Silymarin Content}

The UV Actual Silymarin Content (ASC, expressed as silybin equivalents), of the commercial milk thistle extract (MTE) resulted of $91.06 \% \pm 2.3$, while the $29.0 \% \pm 0.8$ of the total active content by HPLC was quantified in silybin, in agreement with the producer specifications (silymarin $\geq 90 \%$; silybin A and B > 25\%). These high levels of functional active substances have encouraged our research towards the technological improvement of the product to enhance bioavailability after oral intake and to promote its oral administration in in vivo trial.

\subsection{Microencapsulation Process}

The obtained results concerning yield, encapsulation efficiency, and particle size have been reported in Table 1. Preliminary experiments on liquid feed preparation have highlighted two issues of particular importance. The MTE raw extract has poor wettability which makes particularly tricky the development of feed suspensions for the spray-drying process (prolonged times of agitation, heating and ultrasound sonication). The non-homogeneous suspension could negatively affect the atomization process (nozzle clogging, pressure drop, flow disruptions) resulting in meager production yield and inadequate particle morphology (coating surfaces routes, partial amorphization, presence of non-encapsulated crystals of extract). A small percentage of SLS as a surfactant $(0.005 \% w / v$ of SLS) was directly added to the water medium used to prepare the solvent system to overcome the low wettability of MTE. Safety studies on SLS reported the oral toxic dose (human) at $0.5-5 \mathrm{~g} / \mathrm{kg}$ [38]. It has been deemed safe by many investigatory pharmaceutical associations in small doses [39]. The concentration of SLS used in our study was calculated by assuming that generally in a unit dose weight of $500 \mathrm{mg}$ for solid dosage form prepared as immediate-release (IR) formulation there are $10 \mathrm{mg}$ of SLS [40]. By the SLS percentage used to prepare the liquid feed $(0.005 \% w / v)$, the final formulation may contain a maximum (without considering the process loss) of $2.5 \mathrm{mg}$ SLS in 500-mg unit dose which is very far from the toxic dose.

Table 1. Composition and characteristics of raw materials and microparticles.

\begin{tabular}{cccccccc}
\hline Samples & Yield $\%$ & ${ }^{\mathbf{a}}$ TEC $\%$ & ${ }^{\mathbf{b}}$ TSC $\%$ & ${ }^{\mathrm{c}}$ ASC $\%$ & ${ }^{\mathbf{d}}$ AEC $\%$ & ${ }^{\mathbf{e}}$ EE $\%$ & $\mathbf{d}_{\mathbf{5 0}} \boldsymbol{\mu m}(\mathbf{s p a n )}$ \\
\hline NaCMC & - & - & - & - & - & - & $21.1(1.1 \pm 0.2)$ \\
MTE & - & - & - & $91.1 \pm 2.3 *$ & - & - & $19.1(2.5 \pm 0.9)$ \\
Blank_mp & $74.9 \pm 3.7^{*}$ & - & - & - & - & - & $3.9(1.9 \pm 0.4)$ \\
MTE_mp & $69.7 \pm 4.1^{*}$ & 50 & 45.5 & $38.6 \pm 0.6^{*}$ & $42.4 \pm 0.6^{*}$ & $84.9 \pm 0.6^{*}$ & $4.4(2.7 \pm 0.8)$ \\
\hline
\end{tabular}

The so made suspension could be processed by spray-drying resulting in satisfactory production yield (69.7\%). NaCMC was useful as an encapsulant agent leading to an $\mathrm{ASC}_{\mathrm{MTE}}(38.6 \%)$ extremely close to the theoretical value $(45.5 \%)$ which resulted in a high encapsulation efficiency (84.9\%). The functionality of MTE is correlated to the silymarin content, the higher the $\mathrm{ASC}_{\mathrm{MTE}}$ in the produced encapsulated powder form is, the higher should be the final formulation functional activity, thus, the obtained encapsulation efficiency is an exciting and promising characteristic.

\subsection{Powder Characterization}

\subsubsection{Dimensions and Morphology}

Results of dimensional analysis (Table 1) indicated that MTE_mp powder system had very narrow size distribution $(4.4 \mu \mathrm{m})$ to MTE raw extract $(19.1 \mu \mathrm{m})$. The span value used to describe the distribution 
width correlating the distribution of particle population, and derived by a model-independent algorithm resulted lower than 3, defining that the volume of particles distribution (distribution width) was in a narrow range. The morphological study showed that MTE raw extract is material in crystalline state (Figure 1a) with high size, irregular shape, and surface; otherwise, MTE_mp (Figure 1b) is formed by small, well-formed, and spherically shaped microparticles with few aggregates and severe reduction in crystallinity. No pores onto the surface, able to promote the loss of the core material, were detected. Decreasing in both particle size and crystallinity increases the surface area exposed to the dissolving solvent and enhance the dissolution rate [41].
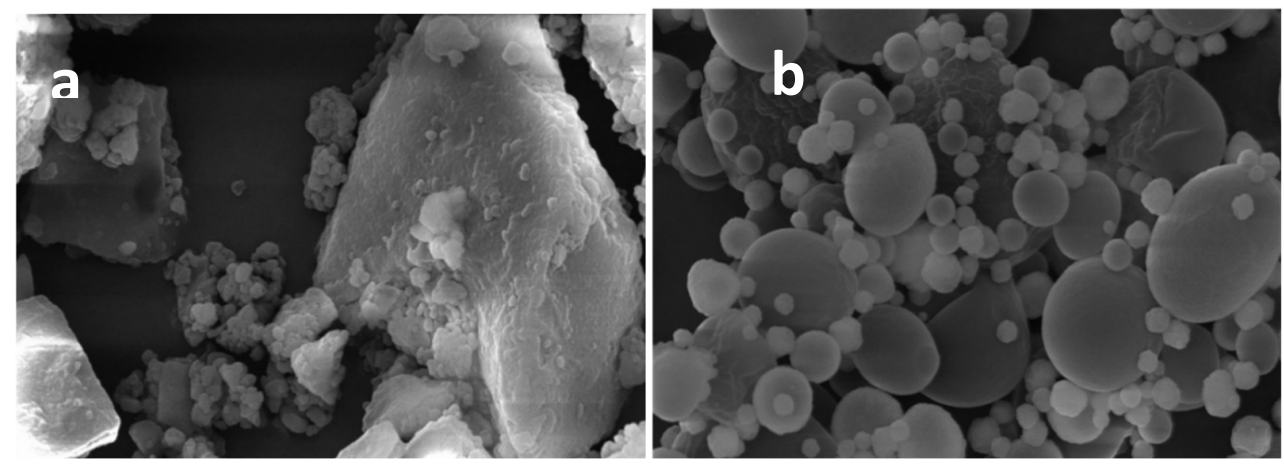

Figure 1. Scanning electron microscopy of MTE raw extract (a) and spray dried MTE_mp (b).

FM images (Figure 2) confirmed the crystalline state of MTE raw extract also showing it well embedded within the NaCMC matrix in the MTE mp system. Crystalline raw extract (Figure 2a) has a characteristic yellow fluorescence. MTE_mp microparticles (Figure 2b) show a light blue fluorescence due to flavonoids well embedded within the matrix.
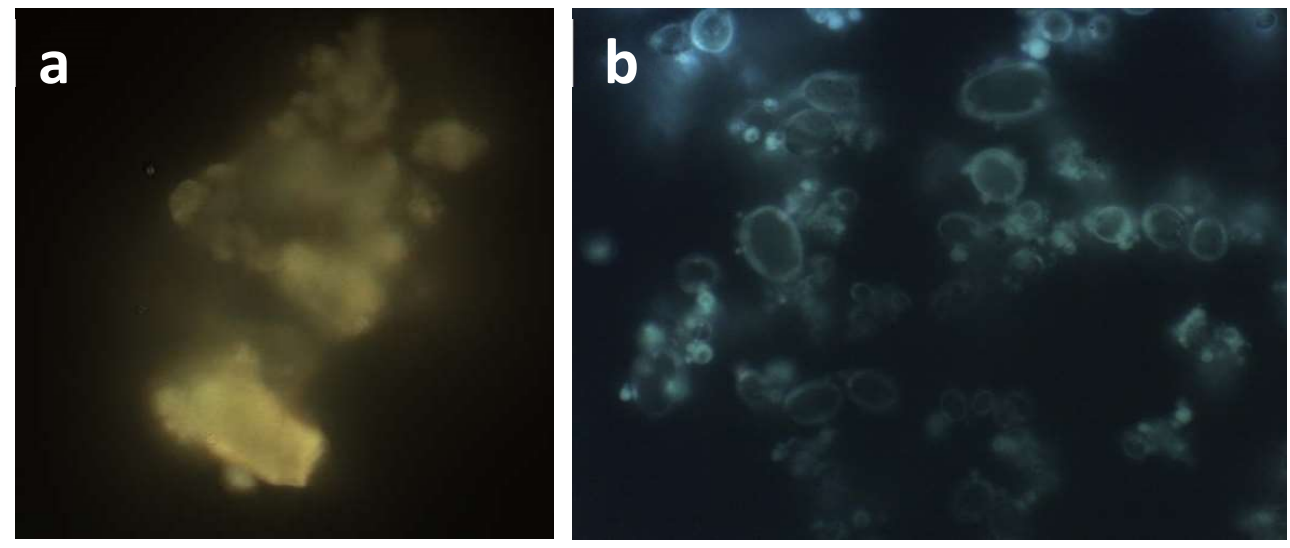

Figure 2. Fluorescence microscopy of crystalline MTE raw extract (a) and MTE_mp microparticles (b).

\subsubsection{Thermal Analysis, TGA and PXRD}

The variation in the solid state (amorphous/crystalline ratio) of MTE_mp and blank_mp (loaded and unloaded microparticles) to MTE raw extract, was confirmed by DSC (Figure 3). This analysis was also performed to verify the absence of degradation events, possibly occurring during the spray drying process, which could alter the extract functionality. In Figure 3 the thermal trend of MTE raw extract shows the presence of free water (residual humidity; endothermic event around $70{ }^{\circ} \mathrm{C}$ ), attributable to dehydration of the sample. The two subsequent endothermic events are due to the melting of solid state. In particular, the first endothermic event exhibits a melting point at $\mathrm{T}=121.43{ }^{\circ} \mathrm{C}$ and a peak visible at $\mathrm{T}=128.72{ }^{\circ} \mathrm{C}$. The second endothermic event exhibits a melting point at $\mathrm{T}=138.98{ }^{\circ} \mathrm{C}$ with a peak visible at $\mathrm{T}=151.95^{\circ} \mathrm{C}$. After the last endothermic event at $\mathrm{T}=276.04{ }^{\circ} \mathrm{C}$, the final degradation 
starts at temperatures above $280{ }^{\circ} \mathrm{C}$ due to the presence of sugars in the extract. In the thermal profile of MTE_mp powder, the thermal trend of the original material was not detectable, suggesting that MTE was well encapsulated/embedded in the matrix also confirming the good physical interaction with the polymer used as the encapsulant. The spray-drying process, combined with the use of NaCMC and surfactant-water/organic solvent system, allows the conversion of the extract into an amorphous state with a functional interaction in forming homogeneous matrix system. Moreover, no degradation peaks, attributable to chemical or physical instability were detected.

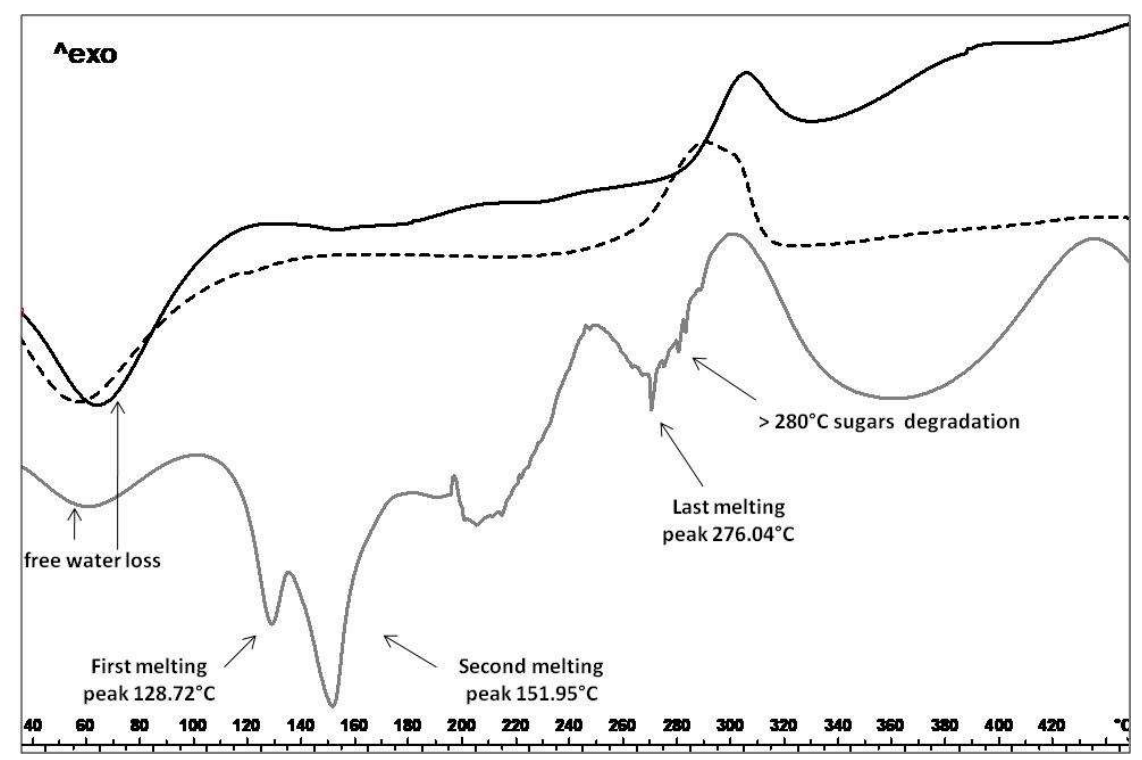

Figure 3. Differential scanning calorimetry analysis. MTE raw extract thermal profile (grey line); MTE_mp (black line) and blank_mp (dotted line).

To further confirm the dehydration of MTE_mp in the range from room temperature to $85^{\circ} \mathrm{C}$, TGA analysis was also performed. The TG-DTG profile of MTE_mp, reported in Figure 4, exhibits a single weight loss of $\sim 10 \%$. This weigh loss is probably due to residual humidity (loss of free water) still present in the sample.

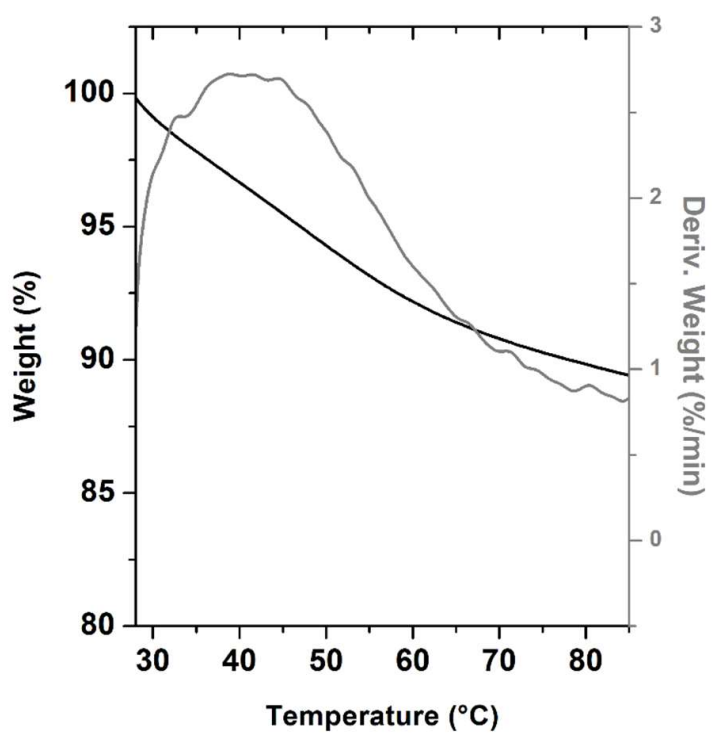

Figure 4. Thermogravimetric analysis. TG-DTG (black line and gray line, respectively) profile of MTE_mp. 
In agreement with results of SEM and DSC analysisis, MTE_mp powder resulted completely amorphous as indicated by PXRD profiles (Figure 5). The diffraction pattern of the MTE raw extract (Figure 5, gray line) shows, in the range between $12^{\circ}$ and about $50^{\circ}$ of $2 \vartheta$, a series of typical reflections of crystalline silymarin complex [42]. In the MTE_mp pattern, all the peaks of MTE raw extract disappeared. It exhibits only a unique large hump at about $20^{\circ}$ of $2 \vartheta$ angle (Figure 5 , black line), as typical of amorphous materials. This result indicates that MTE raw extract was successfully encapsulated into MTE_mp microparticles.

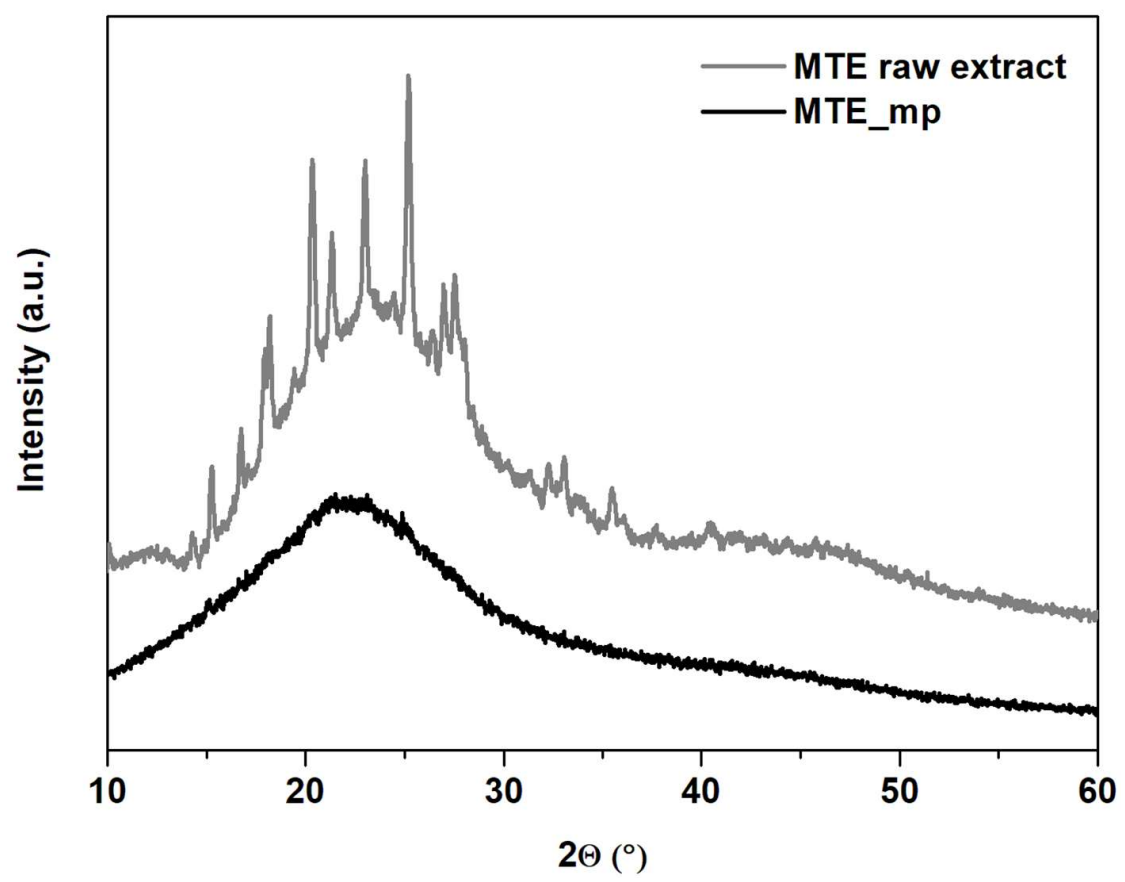

Figure 5. XRD analysis. Diffraction patterns of MTE raw extract (gray line) and MTE_mp (black line).

\subsection{Solubility and Dissolution Profiles}

Results from solubility assay $(25.5 \pm 3.8 \mathrm{mg} / \mathrm{L})$ classified MTE raw extract as a very slightly soluble material [43], and a very slow water dissolution rate was indicated by in vitro dissolution tests (Figure 6).

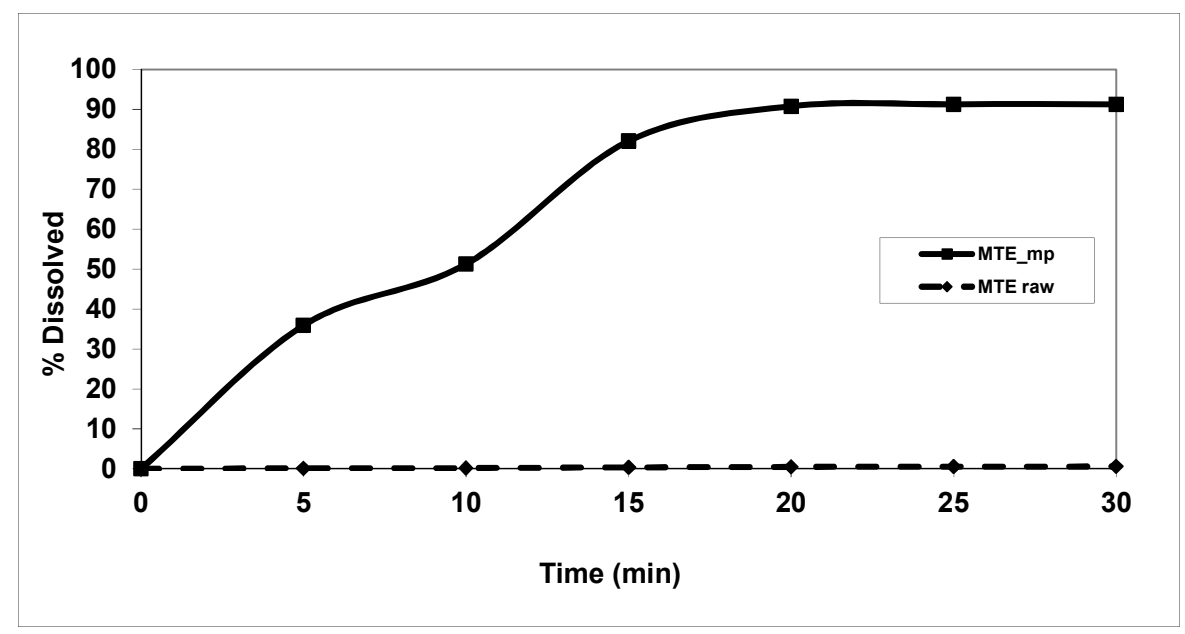

Figure 6. In vitro dissolution profiles of MTE_mp (black line) and MTE extract raw (dotted line) (standard deviation data $<1 \%$ ). 
After $30 \mathrm{~min}$, the MTE raw extract dissolution rate in water is drastically low, with an average value, graphically expressed as the percentage of dissolution to the time, lower than $1 \%$ (about $0.4 \mathrm{mg}$ of raw extract). The dissolution/release profiles of MTE_mp showed a fast enough active content release from the polymeric system with a high increase in dissolution rate until $80 \%$ at $15 \mathrm{~min}$ and $90 \%$ at $30 \mathrm{~min}$ to about $0.5 \%$ and $1 \%$, respectively, for MTE raw extract. The increase of the microparticle-water interaction, due to both small and amorphous physical state of the material and hydrophilic and water-sorption properties of $\mathrm{NaCMC}$ combined with surfactant activity of SLS.

\subsection{Permeation Studies}

Transport through membranes is crucial for an active ingredient such as MTE_mp which must cross any bio-membrane surface to be absorbed in vivo after oral or topical administration (Figure 7). Moreover, for in vitro testing of permeation through the membranes, the release of active substances from the ingredient or formulation is often examined, allowing the comparison of formulations or quality control $[29,44]$. Franz type vertical diffusion with the artificial membrane was used to study the rate of the silymarin release from both MTE raw extract and MTE_mp powder with the aim to provide useful information about the quality of the ingredients and also to estimate how the microencapsulation process and differences in solid state may influence the permeation process through a membrane. The unprocessed extract showed slower silybin permeation $\left(3.6 \mu \mathrm{g} / \mathrm{cm}^{2}\right.$ at $\left.180 \mathrm{~min}\right)$ through membrane than MTE_mp which results in 5-fold higher $\left(18.9 \mu \mathrm{g} / \mathrm{cm}^{2}\right.$ at $\left.180 \mathrm{~min}\right)$ (Figure 7). The amorphous microencapsulated form enhances powder wettability and, therefore, the affinity between the solid and the liquid medium.

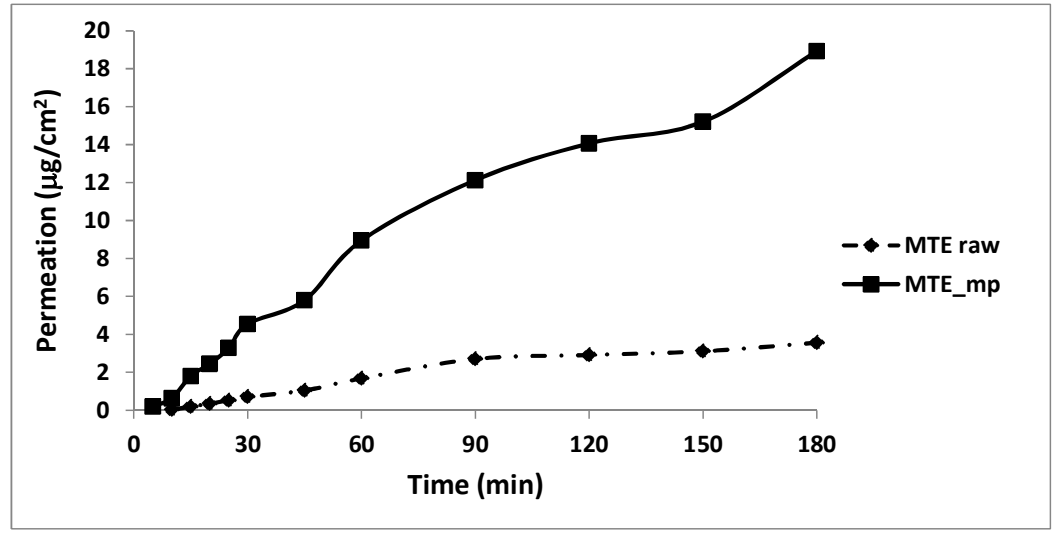

Figure 7. In vitro permeation profile. MTE raw extract (dotted line) and MTE_mp (black line) (standard deviation data $<1 \%$ ).

\subsection{Biological Assays}

DC progenitors are dynamically regulated to reduce their inflammatory phenotype by the intestinal milieu. DCs tolerance is imprinted by tissutal factors, particularly in an anatomical compartment exposed to a large variety of antigens [45]. In the intestine, nutritional-derived factors contribute to DCs polarization. The anti-inflammatory effects of silymarin have already been demonstrated [46]. Naturally derived compounds, like polyphenols and flavonoids, are a potential target for new therapies against chronic inflammatory syndromes due to their ability to reduce pro-inflammatory cytokine secretion and antigen presentation. We compared the anti-inflammatory properties of raw extract and microencapsulated MTE using in vitro cultured murine dendritic cells exposed to LPS as inflammatory stimulus (Figure 8). DCs were exposed to different MTE raw extract and MTE_mp powder concentrations at day 7, lipopolysaccharide was administered in the culture dish at day $8.24 \mathrm{~h}$ later the supernatant was collected and cells were counted, stained using anti-CD11C and anti-MHCII antibodies and analyzed by FACS (Figure 9). ELISA detected the concentration of inflammatory cytokines released in the supernatant. 

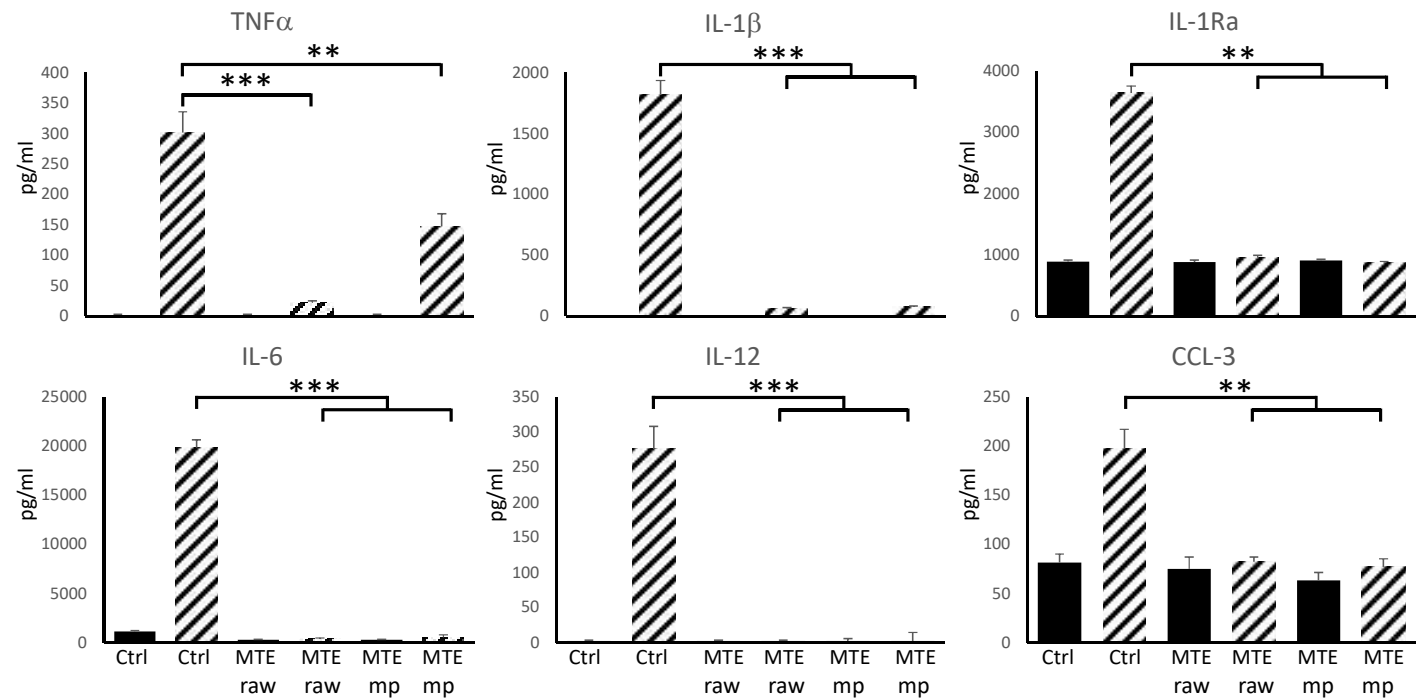

Figure 8. Cytokine secretion by DCs exposed to MTE. Patterned bars represent cytokine concentration in the supernatant of DCs $24 \mathrm{~h}$ after LPS administration. DCs exposed to MTE raw material $(0.312 \mathrm{mg} / \mathrm{mL})$ or MTE_mp $(0.625 \mathrm{mg} / \mathrm{mL})$ fail to produce inflammatory cytokines. MTE exposed DCs in the absence of LPS (filled bars) did not secrete inflammatory cytokines. Data are shown as mean \pm S.D. of five independent experiments; ${ }^{* *} p<0.01,{ }^{* * *} p<0.001$.

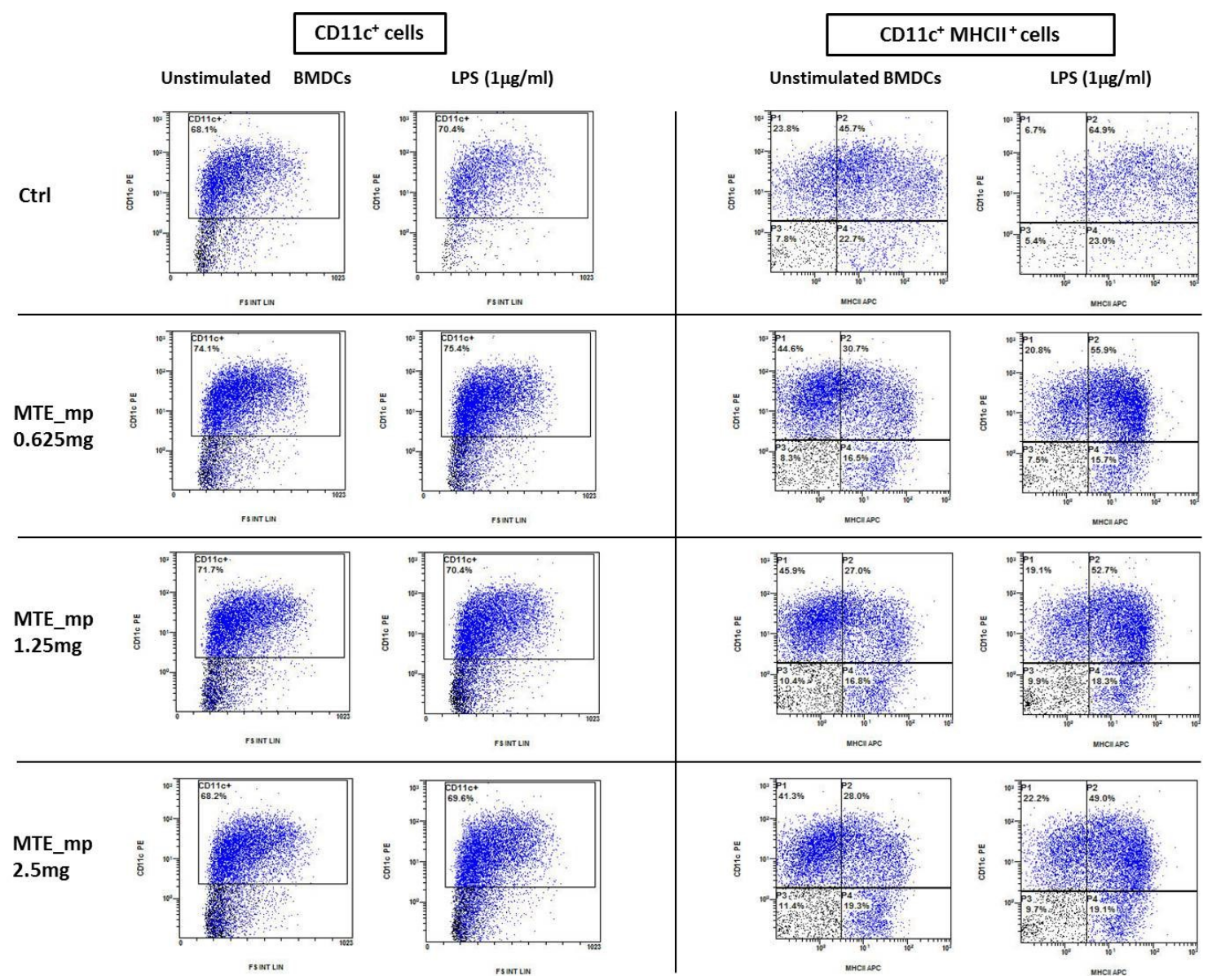

Figure 9. Dendritic cells (CD11C+) do not decrease much even at the highest concentration. MHCII expression decreases after LPS, this is consistent with less maturation and anti-inflammatory effect. 
Figure 8 shows TNF $\alpha$, IL-1 $\beta$, IL-6, and IL-12 reduction following both MTE raw extract and MTE_mp powder administration.

The secretion of the inflammatory cytokines TNF $\alpha$, IL- $1 \beta$, and IL-12 is severely reduced using $0.312 \mathrm{mg} / \mathrm{mL}$ of MTE raw extract, while for the MTE_mp it is necessary to reach $0.625 \mathrm{mg} / \mathrm{mL}$. As demonstrated by similar experiments, IL-6 is reduced even by a lower concentration of flavonoids. Finally, the baseline production of the chemokine CCL-3 and the anti-inflammatory IL1-Ra does not appear to be affected by MTE raw extract and MTE_mp exposure, but both compounds prevent the increased secretion observed following LPS administration. DCs exposed to MTE lose their ability to secrete inflammatory cytokine even following LPS administration.

Here we demonstrate the possibility to reduce TNF $\alpha$, IL- $1 \beta$, IL-6, and IL-12 using $0.625 \mathrm{mg} / \mathrm{mL}$ of microencapsulated MTE. As reported for other naturally-derived bioactive compounds [36,37] DCs exposure to silymarin microparticles or raw extract prevents LPS-mediated inflammatory cytokine secretion. Apparently, MTE raw extract was already efficient at lower concentration $(0.312 \mathrm{mg} / \mathrm{mL})$ than MTE_mp $(0.625 \mathrm{mg} / \mathrm{mL})$. This result is depending on the extract content of the MTE_mp formulation (see Table 1). The extract content of MTE_mp is $42.4 \%$, so in $0.625 \mathrm{mg}$ there is about $0.265 \mathrm{mg}$ of extract. This MTE active amount is lower than the effective dosage of MTE raw extract $(0.312 \mathrm{mg} / \mathrm{mL})$ meaning an enhancement of the functionality of the extract in microparticulate powder form. Thus, the functionality was positively affected by the process. MTE raw extract is a not dispersible material in water; instead, the innovative amorphous microparticulate MTE_mp avoid this limitation, enhancing the powder wettability also well-affecting the anti-inflammatory properties of the MTE raw extract. This feature makes MTE a water-soluble and drinkable extract, so giving the opportunity to develop new strategies for MTE delivery in clinical treatments.

\subsection{Stability Studies and Antioxidant Activity}

MTE is a rich source of flavonolignans belonging to classe of polyphenols. Unfortunately, these compounds, well known for their broad spectrum of biological properties $[14,47,48]$ react readily with various components and undergo to oxidation/degradation process with consequent functionality decrease. The recommendations of the manufacturer to store silybin standard are to keep it at $4{ }^{\circ} \mathrm{C}$ away from light to avoid degradation. Thus, to verify stabilization of encapsulated extract in our microparticle system, accelerated stability studies of MTE_mp powder to MTE raw extract have been performed [49]. After six months, no significant decrease (lower than 1\%) in Silybin content was recorded by HPLC method [50]. Moreover, the free-radical scavenging activity, before and after the spray-drying process, and until six months of storage, was evaluated. In the DPPH test, a validated assay for screening the antiradical activity of extracts or natural compounds [17,51], MTE showed a significant dependent-concentration free radical scavenging activity (expressed as $\mathrm{EC}_{50}$ ). The effect remained unaltered after spray drying process (Table 2). Notably, no loss of activity has been observed for MTE-mp powder during six months of harsh storage conditions (Table 2). On the contrary, during the same time, the $\mathrm{EC}_{50}$ value of MTE raw extract is going to reduce from $25.2 \pm 1.2 \mu \mathrm{g} / \mathrm{mL}$ (0 months) to $71.2 \pm 2.9 \mu \mathrm{g} / \mathrm{mL}$ (6 months). This result highlights that NaCMC is a carrier able not only to enhance the solubility properties but also to protect the functionality of the extract. The developed microencapsulation process is efficient to produce long-lasting, stable microparticulate powder systems.

The test was performed until six months of storage. At the time point, three withdrawals for three different samples of each batch were carried out. $\alpha$-Tocopherol was used as positive control of the $\mathrm{DPPH}$ assay. Data are mean $\pm \mathrm{SD}$. ${ }^{* *} p<0.002$ (vs. $\mathrm{EC}_{50}$ at $\mathrm{t}_{0}$ ). 
Table 2. Free-radical scavenging activity (DPPH test) expressed as the concentration of $\mu \mathrm{g} / \mathrm{mL}$ of sample necessary to decrease the initial DPPH concentration by $50 \%\left(\mathrm{EC}_{50}\right)$ of the extract before (MTE raw extract) and after (MTE_mp) the microencapsulation process.

\begin{tabular}{ccccc}
\hline Materials & \multicolumn{4}{c}{ Months } \\
\hline & 0 & 1 & 3 & 6 \\
MTE raw extract & $25.2 \pm 1.2$ & $51.1 \pm 1.3$ & DPPH test $E C_{50} \mu g / m L$ & \\
MTE_mp & $26.3 \pm 0.9$ & $25.1 \pm 1.4$ & $26.8 \pm 1.9$ & $71.2 \pm 2.9$ \\
$\alpha$-tocopherol & $10.1 \pm 1.3$ & $10.2 \pm 1.1$ & $10.1 \pm 1.1$ & $10.3 \pm 1.2$ \\
\hline
\end{tabular}

\section{Materials and Methods}

\subsection{Chemicals}

Sodium carboxymethylcellulose (NaCMC, medium viscosity, E466) was supplied by Sigma Aldrich (Milan, Italy); Milk thistle extract (MTE) (extract CARDUI MARIANE E FRUCT. SICCUM) code: 345064 batches 248091 ) standardized at $\geq 90 \%$ in silymarin content (expressed as silybin, calculated on anhydrous substance by HPLC), and Rottapharm/Madaus s.p.a supplied silybin as standard. (Monza, Italy). Sodium lauryl sulfate (SLS) from A.C.E.F. s.p.a. (Piacenza, Italy). All other chemicals used were of reagent grade.

\subsection{Liquid Feed Preparation and Spray Drying Conditions}

$\mathrm{A} \mathrm{H}_{2} \mathrm{O} / \mathrm{EtOH} /$ acetone liquid system 50/15/35 (200 mL) containing NaCMC and MTE in a 1:1 weight ratio (total amount $2 \mathrm{~g}$ ), was prepared as follows: $\mathrm{NaCMC}$ was dissolved in surfactant-water with $0.005 \%(\mathrm{~g} / 100 \mathrm{~mL})$ of SLS; then, the organic phase was slowly poured and, finally, the MTE dried extract was added to the polymeric solution under continuous magnetic stirring. A 1\% (g/100 mL) total final concentration was reached. The homogeneous suspension was sonicated for 20 min and the liquid feeds were spray dried (Büchi B-191 Mini Spray Dryer; Büchi Laboratoriums-Technik, Flawil, Switzerland) under the following experimental conditions: inlet/outlet temperatures $100 / 65^{\circ} \mathrm{C}$; spray flow feed rate $5 \mathrm{~mL} / \mathrm{min}$; nozzle diameter $0.5 \mathrm{~mm}$; drying air flow $600 \mathrm{~L} / \mathrm{h}$, air pressure 6 bar, aspirator $100 \%$. The suspensions were gently stirred using a magnetic stirring to keep homogeneity, during the pumping [29]. As a control, a blank batch only with NaCMC plus SLS dissolved in the solvent system without extract (Blank_mp powder), was prepared. Each preparation was carried out in triplicate.

\subsection{Powders Characterization}

\subsubsection{Quantitative Analysis}

UV method. The concentration of silymarin expressed as silybin equivalent, the marker selected for the MTE, was evaluated by measuring absorbance (UV/Vis spectrometer Lambda 25, Perkin Elmer Instruments, Walthan, MA, USA) at $\lambda 288 \mathrm{~nm}$. Calibration curves were previously worked out using $\mathrm{MeOH}$ in $1 \mathrm{~mm}$ cell (Spectracomp 602, Advanced Products Srl, Milan, Italy) and distilled water in $1 \mathrm{~cm}$ cell (Spectracomp 602). Proportionality between absorbance and concentration was verified in the range $50-250 \mathrm{mg} / \mathrm{L}\left(R^{2}>0.999\right)$ for $\mathrm{MeOH}$ and $5-30 \mathrm{mg} / \mathrm{L}\left(R^{2}>0.999\right)$ for water. $40 \mathrm{mg}$ of all samples were dissolved in $40 \mathrm{~mL}$ methanol, shaken and centrifuged for $15 \mathrm{~min}$ at $3000 \times \mathrm{g}$. The supernatants filtered with $0.45 \mu \mathrm{m}$ filters were analyzed. Each analysis was made in triplicate.

HPLC method. An HPLC apparatus was used to evaluate silybin content (Agilent 1100 series system (Agilent, Santa Clara, CA, USA), equipped with a Model G-1312 pump, a $20 \mu \mathrm{L}$ Rheodyne Model G-1322A loop (Agilent, Santa Clara, CA, USA), a DAD G-1315 detector, and a $150 \times 3.9 \mathrm{~mm}$ i.d. $\mathrm{C}-18 \mu$-Bondapack column). Peaks areas were calculated with an Agilent integrator. The solvents were $\mathrm{HCOOH} 0.1 \%$ in $\mathrm{H}_{2} \mathrm{O}$ (solvent $\mathrm{A}$ ) and $\mathrm{HCOOH} 0.1 \%$ in $\mathrm{MeOH}$ (solvent B). Elution gradient: $0 \rightarrow 5 \mathrm{~min}$, $43 \rightarrow 45 \%$ B; $5 \rightarrow 10 \mathrm{~min}, 45 \% \mathrm{~B} ; 10 \rightarrow 115 \mathrm{~min}, 45 \rightarrow 50 \%$ B. Analysis was carried out in triplicate: 
flow rate of $0.8 \mathrm{~mL} / \mathrm{min}$; DAD detector set at $288 \mathrm{~nm}$. Linearity. Silybin reference standard solutions were prepared at three concentration levels $(100-400 \mu \mathrm{g} / \mathrm{mL})$ and injected three times. The standard curve was analyzed using the linear least-squares regression equation derived from the peak area (regression equation $y=2915.3 x-63.725, r^{2}=0.9998$ where $y$ is the peak area and $x$ the concentration).

Specificity. Peak associated with the marker was identified by its retention time $\left(t_{\mathrm{r}}=26.12 \mathrm{~min}\right)$ and confirmed by co-injection with the standard compound.

\subsubsection{Yield and Loading Efficiency}

Production yields were gravimetrically determined (balance Crystal 100 CAL - Gibertini Novate, Milanese, Italy, $\max 110 \mathrm{~g} \mathrm{~d}=0.1 \mathrm{mg} ;+15^{\circ} \mathrm{C} / 30^{\circ} \mathrm{C}$ ) and expressed as the weight percentage of the final product compared to the total amount of the materials sprayed.

The theoretical extract content (TEC) was calculated as the percentage of MTE compared to the initial total content of components (MTE plus $\mathrm{NaCMC}$ ) in the liquid feed before spray-drying.

Actual silymarin content of the unprocessed extract MTE (ASC $\mathrm{MTE}_{\mathrm{MTE}}$ ), and of spray-dried

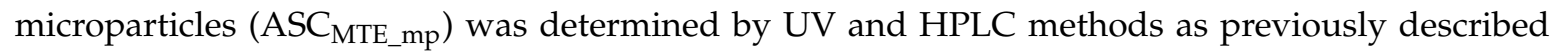
and expressed as silybin equivalents in percentage to $100 \mathrm{mg}$ of powder.

The actual extract content (AEC) was derived by ASC and calculated as:

$$
\mathrm{AEC} \%=\mathrm{ASC}_{\mathrm{MTE} \_\mathrm{mp}} / \mathrm{ASC}_{\mathrm{MTE}} \times 100
$$

The extract encapsulation efficiency (EE\%) was the ratio of the actual to the theoretical extract content:

$$
\mathrm{EE} \%=\mathrm{AEC} / \mathrm{TEC} \times 100
$$

Each analysis was made in triplicate and results expressed as average values.

\subsubsection{Particle Size Analyses}

The dimensional distribution was carried out with a Laser Light Scattering (LLS) granulometer (Beckman Coulter LS 230, Particle Volume Module Plus, Brea, CA, USA). The MTE raw extract was suspended in distilled water; otherwise, microparticles were suspended in isopropanol. About $200 \mu \mathrm{L}$ of the suspension was poured into the small volume cell to obtain an obscuration between 8 and $12 \%$. Particle size distributions were calculated using the Fraunhofer model. The results were expressed as $d_{10}, d_{50}$, and $d_{90}$, indicating the volume diameters at the 10th, 50th and 90th percentiles, of the particle size distribution. The span is defined as:

$$
\text { Span value }=\left(\mathrm{d}_{90}-\mathrm{d}_{10}\right) / \mathrm{d}_{50}
$$

\subsubsection{Morphology}

Morphology of the particles was examined by scanning electron microscopy (SEM) using an EVO MA 10 microscope (Carl Zeiss, Oberkochen, Germany) with a secondary electron detector (Carl Zeiss SMT Ltd., Cambridge, UK) equipped with a EMSCD005 metallizator (LEICA, Oberkochen, Germany) producing deposition of a $200-400 \AA$ thick gold layer. To verify the microparticles uniformity, at least 20 SEM images were taken into account for each observation.

The fluorescent microscopy assays (FM) were performed observing the samples with a Zeiss Axiophot fluorescence microscope, with 40, 63 and $100 \times 1.4$ NA Plan Apochromat oil immersion objectives (Carl Zeiss Vision, München-Hallbergmoos, Germany) using standard DAPI (4',6-diamidino2-phenylindole) optics that adsorb violet radiation $(\max 372 \mathrm{~nm}$ ) and emit a blue fluorescence (max $456 \mathrm{~nm})$. 


\subsubsection{Differential Scanning Calorimetry (DSC)}

Powder samples were analyzed via differential scanning calorimetry on an indium-calibrated Mettler Toledo DSC 822e (Mettler Toledo, Columbus, OH, USA). The instrument automatically determined the blank curve. The baseline correction was previously performed to the sample assays. It was considered as the baseline the separation between the region of latent heat from that of sensible heat; graphically it was the startup deflection proportional to the heat capacity of the sample followed by a DSC curve section with no thermal effects. The integral baseline which takes into account the change in the heat capacity with conversion has been considered. Thermograms were recorded by placing weighed quantities (8-10 mg with a microbalance from MTS Mettler Toledo) of each sample in a $40 \mu \mathrm{L}$ aluminum pan that was sealed and pierced. The samples underwent one dynamic thermal cycle; they were heated from $25^{\circ} \mathrm{C}$ to $450{ }^{\circ} \mathrm{C}$ at a heating rate of $10^{\circ} \mathrm{C} / \mathrm{min}$.

\subsubsection{X-ray Analysis}

The solid state of the samples (MTE raw extract and MTE_mp) was analyzed with a D8 X-ray diffractometer using CuK $\alpha$ radiation $(\lambda=1.54050 \AA$ ) (Bruker, Milano, Italy) operating at $35 \mathrm{kV}$ and $40 \mathrm{~mA}$. The scanning angle ranged from $10^{\circ}$ to $60^{\circ}$ of $2 \vartheta$ and steps were of 0.0296 of $2 \vartheta$. The diffraction patterns were obtained placing into a sample holder an amount of about $300 \mathrm{mg}$ samples.

\subsubsection{Thermogravimetric Analysis}

Thermogravimetric analysis (TG-DTG) at $10^{\circ} \mathrm{C} / \mathrm{min}$ heating rate in air atmosphere from room temperature to $85^{\circ} \mathrm{C}$ was performed with a SDT Q600 Analyzer (TA Instruments, New Castle, DE, USA) coupled with a mass spectrometer. The thermograms were obtained using about $10 \mathrm{mg}$ samples in a standard alumina pan. All the experiments were performed in triplicate.

\subsection{Solubility, Dissolution Tests, and Permeation Profile}

All experiments were made in triplicate; only the mean values are reported (standard deviations $<1 \%$ ).

Solubility. According to the "Farmacopea Ufficiale della Repubblica Italiana" (FUI), an excessive amount of powder was introduced into glass vials containing $8 \mathrm{~mL}$ of $\mathrm{H}_{2} \mathrm{O}$; the samples were stirred and stored at $25{ }^{\circ} \mathrm{C}$ for three days. Then, samples were centrifuged for $15 \mathrm{~min}$ at $3.000 \mathrm{rpm}$, to remove the saturation powder. Supernatants were filtered $(0.45 \mu \mathrm{m}$ filters $)$ and the concentration of the solution was determined by UV method as described before.

In vitro dissolution/release test. All the tests carried out in "sink conditions" ( $<35 \%$ of solubility value): samples of $15 \mathrm{mg}$ were dissolved in $1000 \mathrm{~mL}$ of distilled water on a dissolution test apparatus n.2: paddle, $75 \mathrm{rpm}$ at $37^{\circ} \mathrm{C}$. Instruments: SOTAX AT Smart Apparatus (Basel, Switzerland) online with a spectrophotometer (UV/Vis spectrometer Lambda 25, Perkin Elmer Instruments, Walthan MA, USA). MTE dissolved or released from MTE microparticles (MTE_mp) was measured by UV method as previously reported.

Permeation Profile. The permeation assays were performed using Franz-type vertical diffusion cells (Hanson Research Corporation, Chatsworth, CA, USA) at $37^{\circ} \mathrm{C}$ under continuous stirring (170 rpm) by Teflon-coated lively bars placed in the receptor compartment. Permeation experiments were conducted with Franz cells in a standard configuration using an aqueous suspension $(1 \mu \mathrm{g} / \mu \mathrm{L})$ containing MTE raw extract or MTE_mp powder applied to the diffusion cell as donor phase. The receptor compartment was filled with $7 \mathrm{~mL}$ of distilled water ( $\mathrm{pH} 5.8$ ) and a nitrocellulose membrane (size pores: $0.45 \mu \mathrm{m}$ ) previously set with distilled water was applied between the two compartments (permeation 197 area $1.77 \mathrm{~cm}^{2}$ ). At fixed time, aliquots of $100 \mu \mathrm{L}$ were analyzed by HPLC for silibinin determination as reported above. The amount of the extract permeated per area $(\mathrm{Q})$ for each time interval was calculated using the following Equation (4): 


$$
Q\left(\frac{m g}{c m^{2}}\right)=\frac{V_{R} \times C_{n}+\sum_{i=0}^{n-1} V_{P} \times C_{i}}{A}
$$

where:

$V_{R}$ is the receiver volume;

$C_{n}$ is silybin concentration in the receiver at the time $\mathrm{n}$;

$V_{P}$ is the volume of the removed sample;

$C_{i}$ is silybin concentration in the receiver at the time $\mathrm{n}-1$;

Permeation data were reported as the quantity of permeated silybin per permeation area related to time.

\subsection{Generation and Culture of DC}

DCs precursors were harvested from murine bone marrow (BM). Briefly, BM from the tibiae and femurs of 6- to 8-week-old male C57BL/6 mice were flushed with RPMI and depleted of red blood cells with ACK cell lysing buffer (GIBCO, Life Technologies, Walthan, MA, USA). Cells were plated in 6-well culture plates $\left(1 \times 10^{6}\right.$ cells $/ \mathrm{mL} ; 3 \mathrm{~mL} /$ well $)$ in RPMI supplemented with $10 \%$ heat-inactivated FBS, $100 \mathrm{U} / \mathrm{mL}$ penicillin, $100 \mathrm{mg} / \mathrm{mL}$ streptomycin, $25 \mu \mathrm{g} / \mathrm{mL} \mathrm{rmGM}-\mathrm{CSF}$, and $25 \mu \mathrm{g} / \mathrm{mL}$ rmIL-4 at $37^{\circ} \mathrm{C}$ in a humidified $5 \% \mathrm{CO}_{2}$ atmosphere. On day 3, BMDCs were harvested and plated at $1 \times 10^{6} / \mathrm{mL}$ in 24-well culture plates. DCs were cultured from murine bone marrow as previously described [37]. On day 7 BMDCs were treated with MTE raw extract and MTE_mp. Lipopolysaccharide (LPS) was administered $(1 \mu \mathrm{g} / \mathrm{mL})$ at day 8 and $24 \mathrm{~h}$ later the supernatant $(\mathrm{SN})$ was harvested.

Cytofluorimetric analysis. Cells were stained with Anti-MHC Class II antibodies (clone: M5/114.15.2) and Anti-CD11c-FITC (clone: N418) (Miltenyi Biotec, Bergisch Gladbach, Germany) following manufactures protocol. Flow Cytometer acquisition was performed using NAVIOS (Beckman Coulter, Brea, CA, USA).

\subsection{Enzyme-Linked Immunosorbent Assay (ELISA)}

Cell culture SNs were analyzed to detect the cytokine content. Triplicate of the SN was used to identify TNF $\alpha$, IL-1 $\beta$, IL-1Ra, IL-6, IL-12, and CCL-3 concentration using the ELISA kit (R\&D Systems, Minneapolis, MN, USA: DY410, DY401, DY480, DY406, DY419, and DY450, respectively), as described by the manufacturer.

\subsection{Antioxidant Activity Preservation-Stability Studies}

Harsh storage conditions were assessed as reported by the ICH guidelines [50] at $40 \pm 2{ }^{\circ} \mathrm{C}$; $75 \pm 5 \%$ of RH in a climatic chamber (Climatic and Thermostatic Chamber, Mod.CCP37, AMT Srl, Milan, Italy) for six months. At given times (0, 1, 3 and six months) samples of each batch were collected. The free-radical scavenging activity of MTE raw extract and MTE_mp was evaluated over six months of storage using a modified, published method [49]. The first analysis $\left(\mathrm{t}_{0}\right)$ has been conducted after $48 \mathrm{~h}$ from the formulation.

Samples preparation. After the storage period, $10 \mathrm{mg}$ of MTE raw extract was dissolved in $1 \mathrm{~mL}$ of $\mathrm{MeOH}$. Range concentrations of $50-150 \mu \mathrm{g} / \mathrm{mL}$ were tested. $40 \mathrm{mg}$ of MTE_mp were dissolved in $2 \mathrm{~mL}$ of $\mathrm{MeOH}$ to recover the extract from microparticles. The sample was sonicated $20 \mathrm{~min}$ and centrifuged at $4000 \times g$ for $10 \mathrm{~min}$. The supernatant was dried under vacuum with a rotary evaporator (Rotavapor R-200, Buchi Italia Srl, Cornaredo, Italy). The dried material was dissolved in $\mathrm{MeOH}$ and tested at the same concentrations of MTE raw extract.

Method. $37.5 \mu \mathrm{L}$ of the supernatant was added to $1.5 \mathrm{~mL}$ of daily prepared 1,1-diphenyl-2picrylhydrazyl radical (DPPH) solution $(0.025 \mathrm{~g} / \mathrm{L}$ in $\mathrm{MeOH})$. An equal volume $(37.5 \mu \mathrm{L})$ of the vehicle alone was added to control tubes. Absorbance at $517 \mathrm{~nm}$ was measured $30 \mathrm{~min}$ after starting the reaction on a Thermo Evolution 201 UV-visible spectrophotometer Thermo Fisher, Walthan, MA, 
USA). The DPPH concentration in the reaction medium was calculated from a calibration curve analyzed by linear regression, and $\mathrm{EC}_{50}$ (mean effective scavenging concentration) was calculated using the Litchfield and Wilcoxon test $[44,52](\mu \mathrm{g} / \mathrm{mL}$ of sample necessary to decrease the initial DPPH concentration by $50 \%$ ).

\section{Conclusions}

Constant administration of natural anti-inflammatory factors diluted in the drinking water may become a prevention strategy for susceptible patients, also benefit the healthcare system that may reduce the administration of expensive and often not effective treatments. Clinical translation of these results encountered a significant limitation represented by the poor solubility and bioavailability of these compounds. A case study is our milk thistle extract rich in silymarin complex. Extract loaded microparticles by spray drying were produced with high and reproducible yields and encapsulation efficiency. NaCMC used as coating/swelling polymer in a proper solvent system was able to protect the functionality of the extract. The in vitro dissolution and permeation rates of silymarin were dramatically improved suggesting a higher bioavailability after the oral administration. Silymarin anti-inflammatory abilities were preserved by the encapsulation process as demonstrated by the exposure of the immune cells to MTE_mp. Except for a limited increase in the TNF $\alpha$ secretion, silymarin microencapsulated was as efficient as the raw extract concerning inflammatory cytokine suppression, suggesting that the microencapsulation process didn't affect silymarin efficiency. Our formulation could be the answer to the demand for a functional ingredient which retains its activity over time, easy administrable in the drinking water and bioavailable after the intake. This administration route represents an enormous advantage, especially in the context of nutraceuticals, in intestinal inflammatory syndromes. These results represent the basis for future trials that will validate the efficiency of microencapsulated milk thistle extract administration to prevent or treat chronic inflammatory syndromes.

Author Contributions: Conceptualization, F.S.; Investigation, T.E., S.D.S., M.C., C.C.; Funding acquisition, F.G.; Supervision, M.R.L.; Project Administration, R.P.A.; Methodology, T.M.; Data Curation, P.P; Writing-Original Draft, F.S. and M.R.L

Funding: M.C. was supported by the Italian Ministry of Health, "GR-2011-02347991".

Acknowledgments: The authors, thank MedaPharma/Rottapharm/Madaus s.p.a. for the supply of materials.

Conflicts of Interest: The authors declares that there is no conflict of interest regarding the publication of this paper.

\section{References}

1. Chen, Z.P.; Sun, J.; Chen, H.X.; Xiao, Y.Y.; Liu, D.; Chen, J.; Cai, H.; Cai, B.C. Comparative pharmacokinetics and bioavailability studies of quercetin, kaempferol and isorhamnetin after oral administration of Ginkgo biloba extracts, Ginkgo biloba extract phospholipid complexes and Ginkgo biloba extract solid dispersions in rats. Fitoterapia 2010, 81, 1045-1052. [CrossRef] [PubMed]

2. Puglia, C.; Lauro, M.R.; Tirendi, G.G.; Fassari, G.E.; Carbone, C.; Bonina, F.; Puglisi, G. Modern drug delivery strategies applied to natural active compounds. Expert Opin. Drug Deliv. 2017, 14, 755-768. [CrossRef] [PubMed]

3. Sansone, F.; Picerno, P.; Mencherini, T.; Villecco, F.; D’Ursi, A.M.; Aquino, R.P.; Lauro, M.R. Flavonoid microparticles by spray-drying: Influence of enhancers of the dissolution rate on properties and stability. J. Food Eng. 2011, 103, 188-196. [CrossRef]

4. Cho, H.J.; Jee, J.P.; Kang, J.Y.; Shin, D.Y.; Choi, H.G.; Maeng, H.J.; Cho, K.H. Cefdinir solid dispersion composed of hydrophilic polymers with enhanced solubility, dissolution, and bioavailability in rats. Molecules 2017, 22, 280. [CrossRef] [PubMed]

5. Del Gaudio, P.; De Cicco, F.; Sansone, F.; Aquino, R.P.; Adami, R.; Ricci, M.; Giovagnoli, S. Alginate beads as a carrier for omeprazole/SBA-15 inclusion compound: A step towards the development of personalized paediatric dosage forms. Carbohydr. Polym. 2015, 133, 464-472. [CrossRef] [PubMed] 
6. Cerciello, A.; Auriemma, G.; Del Gaudio, P.; Sansone, F.; Aquino, R.P.; Russo, P. A novel core-shell chronotherapeutic system for the oral administration of ketoprofen. J. Drug Deliv. Sci. Technol. 2016. [CrossRef]

7. Robert, P.; Fredes, C. The encapsulation of anthocyanins from berry-type fruits. Trends in foods. Molecules 2015, 20, 5875-5888. [CrossRef] [PubMed]

8. Zokti, J.; Sham Baharin, B.; Mohammed, A.; Abas, F. Green Tea Leaves Extract: Microencapsulation, Physicochemical and Storage Stability Study. Molecules 2016, 21, 940. [CrossRef] [PubMed]

9. Fredes, C.; Becerra, C.; Parada, J.; Robert, P. The microencapsulation of maqui (Aristotelia chilensis (Mol.) Stuntz) juice by spray-drying and freeze-drying produces powders with similar anthocyanin stability and bioaccessibility. Molecules 2018, 23. [CrossRef] [PubMed]

10. Endo, E.H.; Ueda-Nakamura, T.; Nakamura, C.V.; Filho, B.P.D. Activity of spray-dried microparticles containing pomegranate peel extract against Candida albicans. Molecules 2012, 17, 10094-10107. [CrossRef] [PubMed]

11. Lauro, M.R.; Crascì, L.; Giannone, V.; Ballistreri, G.; Fabroni, S.; Sansone, F.; Rapisarda, P.; Panico, A.M.; Puglisi, G. An alginate/cyclodextrin spray drying matrix to improve shelf life and antioxidant efficiency of a blood orange by-product extract rich in polyphenols: MMPs inhibition and antiglycation activity in dysmetabolic diseases. Oxid. Med. Cell. Longev. 2017, 2017. [CrossRef] [PubMed]

12. Lauro, M.R.; Crascí, L.; Sansone, F.; Cardile, V.; Panico, A.M.; Puglisi, G. Development and in Vitro Evaluation of an Innovative "dietary Flavonoid Supplement" on Osteoarthritis Process. Oxid. Med. Cell. Longev. 2017, 2017. [CrossRef] [PubMed]

13. Qavami, N.; Naghdi Badi, H.; Labbafi, M.R.; Mehrafarin, A. A Review on Pharmacological, Cultivation and Biotechnology Aspects of Milk Thistle (Silybum marianum (L.) Gaertn.). J. Med. Plants 2013, 3, $19-37$.

14. Sabiu, S.; Sunmonu, T.O.; Ajani, E.O.; Ajiboye, T.O. Combined administration of silymarin and vitamin C stalls acetaminophen-mediated hepatic oxidative insults in Wistar rats. Braz. J. Pharmacogn. 2015, 25, $29-34$. [CrossRef]

15. Javed, S.; Kohli, K.; Ali, M. Reassessing bioavailability of silymarin. Altern. Med. Rev. 2011, 16, $239-249$. [PubMed]

16. Snima, K.S.; Arunkumar, P.; Jayakumar, R.; Lakshmanan, V.K. Silymarin encapsulated Poly(D,L-lactic-coglycolic acid) nanoparticles: A prospective candidate for prostate cancer therapy. J. Biomed. Nanotechnol. 2014, 10, 559-570. [CrossRef] [PubMed]

17. KÖksal, E.; GÜLÇİN, İ.; Beyza, S.; Sarikaya, Ö.; Bursal, E. In vitro antioxidant activity of silymarin. J. Enzyme Inhib. Med. Chem. 2009, 24, 395-405. [CrossRef] [PubMed]

18. Kidd, P.M. Bioavailability and activity of phytosome complexes from botanical polyphenols: The silymarin, curcumin, green tea, and grape seed extracts. Altern. Med. Rev. 2009, 14, 226-246. [CrossRef] [PubMed]

19. Mohsen, A.M. A Novel Pharmaceutical Formulation (Niosomes) of the Hepatoprotective Drug Silymarin. Ph.D. Thesis, Cairo University, Giza, Egypt, 2008.

20. El-Samaligy, M.S.; Afifi, N.N.; Mahmoud, E.A. Increasing bioavailability of silymarin using a buccal liposomal delivery system: Preparation and experimental design investigation. Int. J. Pharm. 2006, 308, 140-148. [CrossRef] [PubMed]

21. El-Ridy, M.S.; Badawi, A.A.; Safar, M.M.; Mohsen, A.M. Niosomes as a novel pharmaceutical formulation encapsulating the hepatoprotective drug silymarin. Int. J. Pharm. Pharm. Sci. 2012, 4, 549-559.

22. Elmowafy, M.; Viitala, T.; Ibrahim, H.M.; Abu-Elyazid, S.K.; Samy, A.; Kassem, A.; Yliperttula, M. Silymarin loaded liposomes for hepatic targeting: In vitro evaluation and HepG2 drug uptake. Eur. J. Pharm. Sci. 2013, 50, 161-171. [CrossRef] [PubMed]

23. Voinovich, D.; Perissutti, B.; Grassi, M.; Passerini, N.; Bigotto, A. Solid State Mechanochemical Activation of Silybum marianum Dry Extract With Betacyclodextrins: Characterization and Bioavailability of the Coground Systems. J. Pharm. Sci. 2009, 98, 4119-4129. [CrossRef] [PubMed]

24. Qiu, M.; Jia, W.; Li, S.; Xu, Z.; Sun, X.; Wang, X.; Zhang, Y.; Xie, G. A new silymarin preparation based on solid dispersion technique. Adv. Ther. 2005, 22, 595-600. [CrossRef] [PubMed]

25. Zhang, Z.B.; Shen, Z.G.; Wang, J.X.; Zhang, H.X.; Zhao, H.; Chen, J.F.; Yun, J. Micronization of silybin by the emulsion solvent diffusion method. Int. J. Pharm. 2009, 376, 116-122. [CrossRef] [PubMed]

26. El-Samaligy, M.S.; Afifi, N.N.; Mahmoud, E.A. Evaluation of hybrid liposomes-encapsulated silymarin regarding physical stability and in vivo performance. Int. J. Pharm. 2006, 319, 121-129. [CrossRef] [PubMed] 
27. Mohsen, A.M.; Asfour, M.H.; Salama, A.A.A. Improved hepatoprotective activity of silymarin via encapsulation in the novel vesicular nanosystem bilosomes. Drug Dev. Ind. Pharm. 2017, 43, 2043-2054. [CrossRef] [PubMed]

28. Sansone, F.; Esposito, T.; Mencherini, T.; Lauro, M.R.; Del Gaudio, P.; Picerno, P.; Pepe, G.; Aquino, R.P. Particle technology applied to a lactose/NaCMC blend: Production and characterization of a novel and stable spray-dried ingredient. Powder Technol. 2018, 329. [CrossRef]

29. Sansone, F.; Picerno, P.; Mencherini, T.; Russo, P.; Gasparri, F.; Giannini, V.; Lauro, M.R.; Puglisi, G.; Aquino, R.P. Enhanced technological and permeation properties of a microencapsulated soy isoflavones extract. J. Food Eng. 2013, 115, 298-305. [CrossRef]

30. Cal, K.; Sollohub, K. Spray Drying Technique. I: Hardware and Process Parameters. J. Pharm. Sci. 2010, 99, 575-586. [CrossRef] [PubMed]

31. Murugesan, R.; Orsat, V. Spray Drying for the Production of Nutraceutical Ingredients-A Review. Food Bioprocess Technol. 2012, 5, 3-14. [CrossRef]

32. Eri, R.; Chieppa, M. Messages from the inside. The dynamic environment that favors intestinal homeostasis. Front. Immunol. 2013, 4, 1-7. [CrossRef] [PubMed]

33. Rescigno, M.; Urbano, M.; Valzasina, B.; Francolini, M.; Rotta, G.; Bonasio, R.; Granucci, F.; Kraehenbuhl, J.P.; Ricciardi-Castagnoli, P. Dendritic cells express tight junction proteins and penetrate gut epithelial monolayers to sample bacteria. Nat. Immunol. 2001, 2, 361-367. [CrossRef] [PubMed]

34. Niess, J.H. CX3CR1-Mediated Dendritic Cell Access to the Intestinal Lumen and Bacterial Clearance. Science 2005, 307, 254-258. [CrossRef] [PubMed]

35. Chieppa, M.; Rescigno, M.; Huang, A.Y.C.; Germain, R.N. Dynamic imaging of dendritic cell extension into the small bowel lumen in response to epithelial cell TLR engagement. J. Exp. Med. 2006, 203, 2841-2852. [CrossRef] [PubMed]

36. Delvecchio, F.R.; Vadrucci, E.; Cavalcanti, E.; De Santis, S.; Kunde, D.; Vacca, M.; Myers, J.; Allen, F.; Bianco, G.; Huang, A.Y.; et al. Polyphenol administration impairs T-cell proliferation by imprinting a distinct dendritic cell maturational profile. Eur. J. Immunol. 2015, 45, 2638-2649. [CrossRef] [PubMed]

37. De Santis, S.; Kunde, D.; Serino, G.; Galleggiante, V.; Caruso, M.L.; Mastronardi, M.; Cavalcanti, E.; Ranson, N.; Pinto, A.; Campiglia, P.; et al. Secretory leukoprotease inhibitor is required for efficient quercetinmediated suppression of TNF beta secretion. Oncotarget 2016, 7, 75800-75809. [CrossRef] [PubMed]

38. Gleason, M.N.; Gosselin, R.E.; Hodge, I.C. Clinical Toxicology of Commercial Products, 5th ed.; Williams and Wilkins: Baltimore, MD, USA, 1984; p. II-274.

39. Jain, A.; Ran, Y.; Yalkowsky, S.H. Effect of pH-sodium lauryl sulfate combination on solubilization of PG-300995 (an anti-HIV agent): A technical note. AAPS PharmSciTech 2004, 5, e45. [CrossRef] [PubMed]

40. Rege, B.D.; Yu Lawrence, X.; Hussain, A.S.; Polli, J.E. Effect of common excipients on Caco-2 transport of low-permeability drugs. J. Pharm. Sci. 2001, 90, 1776-1786. [CrossRef] [PubMed]

41. Sansone, F.; Mencherini, T.; Picerno, P.; Esposito, T.; Del Gaudio, P.; Russo, P.; Pepe, G.; Lauro, M.R.; Aquino, R.P. Microencapsulation by spray drying of Lannea microcarpa extract: Technological characteristics and antioxidant activity. J. Pharm. Pharmacogn. Res. 2014, 2, 100-109.

42. Ma, Y.; He, S.; Ma, X.; Hong, T.; Li, Z.; Park, K.; Wang, W. Silymarin-loaded nanoparticles based on stearic acid-modified Bletilla striata polysaccharide for hepatic targeting. Molecules 2016, 21. [CrossRef] [PubMed]

43. Farmacopea Ufficiale Italiana, 12th ed.; Istituto poligrafico dello stato: Roma, Italy, 2008.

44. Sansone, F.; Esposito, T.; Mencherini, T.; Piccinelli, A.L.; Gazzerro, P.; Picerno, P.; Russo, P.; Del Gaudio, P.; Essolito, M.; Campiglia, P.; et al. Annurca peel extract: From the chemical composition, through the functional activity, to the formulation and characterisation of a topical oil-in-water emulsion. Nat. Prod. Res. 2016, 30. [CrossRef] [PubMed]

45. Rescigno, M.; Chieppa, M. Gut-level decisions in peace and war. Nat. Med. 2005, 11, 254-255. [CrossRef] [PubMed]

46. Fordham, J.B.; Raza Naqvi, A.; Nares, S. Leukocyte production of inflammatory mediators is inhibited by the antioxidants phloretin, silymarin, hesperetin, and resveratrol. Mediators Inflamm. 2014, 2014. [CrossRef] [PubMed]

47. Pagliarulo, C.; Sansone, F.; Moccia, S.; Russo, G.L.; Aquino, R.P.; Salvatore, P.; Di Stasio, M.; Volpe, M.G. Preservation of Strawberries with an Antifungal Edible Coating Using Peony Extracts in Chitosan. Food Bioprocess Technol. 2016. [CrossRef] 
48. Lovelace, E.S.; Maurice, N.J.; Miller, H.W.; Slichter, C.K.; Harrington, R.; Magaret, A.; Prlic, M.; De Rosa, S.; Polyak, S.J. Silymarin suppresses basal and stimulusinduced activation, exhaustion, differentiation, and inflammatory markers in primary human immune cells. PLoS ONE 2017, 12, e0171139. [CrossRef] [PubMed]

49. Sansone, F.; Picerno, P.; Mencherini, T.; Porta, A.; Lauro, M.R.; Russo, P.; Aquino, R.P. Technological properties and enhancement of antifungal activity of a Paeonia rockii extract encapsulated in a chitosan-based matrix. J. Food Eng. 2014, 120, 260-267. [CrossRef]

50. Abraham, J. International Conference on Harmonisation of Technical Requirements for Registration of Pharmaceuticals for Human Use. In Handbook of Transnational Economic Governance Regimes; Brill: Leiden, The Netherlands, 2009; pp. 1041-1054.

51. Esposito, T.; Sansone, F.; Franceschelli, S.; Del Gaudio, P.; Picerno, P.; Aquino, R.; Mencherini, T. Hazelnut (Corylus avellana L.) Shells Extract: Phenolic Composition, Antioxidant Effect and Cytotoxic Activity on Human Cancer Cell Lines. Int. J. Mol. Sci. 2017, 18, 392. [CrossRef] [PubMed]

52. Piccinelli, A.L.; Pagano, I.; Esposito, T.; Mencherini, T.; Porta, A.; Petrone, A.M.; Gazzerro, P.; Picerno, P.; Sansone, F.; Rastrelli, L.; et al. HRMS Profile of a Hazelnut Skin Proanthocyanidin-rich Fraction with Antioxidant and Anti-Candida albicans Activities. J. Agric. Food Chem. 2016, 64, 585-595. [CrossRef] [PubMed]

Sample Availability: Samples of the compounds MTE_mp powders are available from the authors. 